\title{
ENTREVISTA A CRISTINA PERI ROSSI
}

\author{
POR \\ GUSTAVO SAN ROMÁN \\ University of St. Andrews
}

\begin{abstract}
El material que sigue surge de una entrevista que tuve con Cristina Peri Rossi en Barcelona en diciembre de 1986. Las respuestas de la autora han sido ordenadas, por temas, en diez secciones.
\end{abstract}

1. LA HISTORIA DE "ESTATE VIOLENTO" (CUENTO DE LA REBELIONN DE LOS NIÑOS, 1980)

Creo que sucedió en 1977. Estábamos Julio [Cortázar] y yo paseando en la Fundación Miró, que a los dos nos gustaba mucho, y de repente Julio me dice:

-Tenés que escribir un cuento.

Como éramos muy parecidos, a veces nos contábamos cosas que eran del otro; él me decía que había cosas que le pasaban a él pero que eran mías, y a mí por mi parte me pasaban cosas que eran de él. De manera que cuando nos pasaban cosas así, nos las adjudicábamos:

-Esto es tuyo; realmente me pasó a mi, pero es tuyo.

Entonces ese día en la Fundación me dice:

- Tenés que escribir un cuento.

- ¿Qué pasa?

-Mirá, el otro día [él vivía todavía en Rue de l’Éperon, en un tercer o cuarto piso sin ascensor] estaba subiendo la escalera de mi edificio - hay una vecina, una muchacha joven, muy bonita, yo no la conozco, solamente nos saludamos y ella no sabe quién soy. El otro día al subir la escalera, la vi subir muy agitada. Me pareció que tenía que hablarle, y le dije:

- ¿La puedo ayudar, le ocurre algo?

Y ella me dijo:

-El tigre me miró.

Yo le dije: ¿Cómo?

Y ella:

-Fui al zoológico, y el tigre me miró.

$Y$ entonces, yo le digo: 

amiga:

-Julio, hace poco, estaba lloviendo, y cuando paró de llover, le dije a mi

-Llevame al zoológico.

Yentonces llamamos a un par de amigos y nos fuimos los cuatro al zoológico. Acababa de llover.

-Yo quiero ir al zoológico, les dije, porque ahora no hay nadie. Entonces fuimos, entramos, no había nadie, yo me dirigí a la parte de los felinos. Y de repente, estoy llegando y veo que el puma está de pie y agarrado de los barrotes, gritando enloquecido. Y hay una mujer y un hombre, gorditos, bajitos, y la mujer está muy asombrada - una mujer de unos 50 o 60 años- muy asombrada porque la pantera - un puma o una pantera, no me acuerdo-- está gritando desesperada. Y entonces yo me quedo estacionada un poco para atrás, y viene un cuidador y le dice a la mujer:

-Salga de aquí, señora, usted no se da cuenta pero está excitando al puma.

La mujer dice:

-Pero si yo no le hago nada.

-No, no, váyase, ¿no ve que lo pone nervioso?

Entonces la mujer se va, y el puma, agarrado así a los barrotes, la va mirando, la va siguiendo... Yo me quedé alucinada. Se ve que el olor o algo que el animal captó, ¿no? Entonces, claro, Julio me dijo eso, y escribí el cuento.

\section{EL EXILIO}

Yo creo que eso, la preocupación con la otredad, se ha vuelto especialmente grave a partir de que estoy aquí. Es decir, para mí el exilio ha sido una reflexión obligada sobre lo otro, otro tiempo y otro espacio. Cuando yo llegué aquí, tenía 29 años, y España me pareció horriblemente atrasada con relación a de donde veníamos nosotros. Aquí no habían leído a Virginia Woolf, no sabían quién era Salinger, no habían leído a Dylan Thomas ... Es decir, el mundo referencial de uno no estaba - no habían leído a los existencialistas, no habían visto las películas que nosotros habíamos visto... Yo sentí que había viajado en el espacio y que viajando en el espacio habia viajado en el tiempo. Ni siquiera a mi infancia, porque en mi infanciayo veía películas sobre los campos de concentración nazis, y aquí no se veían. Entonces sentí que había un desplazamiento y que había que empezar de muy atrás. Ahora yo me doy cuenta de que solamente la locura me hizo publicar determinadas cosas aquí que no podían ser entendidas. La literatura seguía siendo decimonónica aquí en España, aparte de que se puede discutir sobre si España está condenada a ser realista porque ganó Sancho y no hay vuelta que darle, ¿no? Y es así, mataron a Don Quijote, y se acabó.

Empecé a vivir en lo otro, y claro, lo otro te provoca desconfianza, tenés que establecer además algunos puentes de contacto. Me sentí mucho menos otra, por ejemplo, en Berlín. 
3. LAS VARIACIONES DEL ESTILO, COMO OCURRE EN LOS DOS DISCURSOS DE LOS MUSEOS ABANDONADOS (1969)

Hay una cosa que para mf́ es básica, que creo que la demuestro en los libros, y que a lo mejor la tengo que decir explícitamente. Estoy muy en contra de lo de que "el escritor es un estilo". Me parece que un estilo siempre es reductivo. Tener un estilo es tener un solo ángulo para mirar la realidad. Cuando mirás por el caleidoscopio, ves nada más que una estructuración de los vidrios. Mi sueño nunca fue tener un estilo reconocible, en la medida en que creo que Kafka es agotador. A mí me gusta muchísimo Kafka, pero la realidad no es sólo Kafka. Hay tantos discursos sobre la realidad, y a lo mejor la realidad no es más que los discursos sobre la realidad. Y tantos discursos sobre la realidad pueden sumar una visión más compleja sobre la realidad. Y esto lo he discutido incluso con Cortázar: repetir un estilo puede también ser una parodia. Si lo que es fresco, lo que es en algún momento valioso como percepción lo convertís en un estilo, se acabó.

Yo sé que puedo escribir un cuento así como "Los extraños objetos" y también otros estilísticamente distintos como los demás de Los museos abandonados. Entonces me parece que si no quiero reducir la visión del mundo a una sola, si no quiero ser "la visión única de Cristina Peri Rossi", porque sería reductivo, no hay más remedio que variar. Porque variar el estilo implica variar la relación con el mundo. Cuando se tiene un estilo se sacrifica la visión del mundo, porque no todo se puede escribir de manera kafkiana. De la misma manera García Márquez sacrifica su visión de la realidad; al ser solamente ésta lo real maravilloso tiene que limitarse a los temas que son susceptibles de lo real maravilloso. Y no todos lo son. De la misma manera que no todo es contable narrativamente, y hay que escribir poesía también, porque la poesía es otra manera de ver las cosas.

\section{ENUMERACIONES Y DIGRESIONES}

Pienso que por un lado hay un pecado de esteticismo que uno cuando es muy joven comete - Borges decía que cuando es joven uno es barroco. Por otro lado para mí las palabras son muy vivas. Yo cuando era una niña de dos o tres años había visto esos diccionarios antiguos en que por ejemplo cuando empezaba la letra $\mathrm{A}$, venía muy adornada la primera $\mathrm{A}$ y había una cantidad de objetos que empezaban con A, y yo estaba convencida de que cada palabra era un cajón, un arca, y que adentro estaban todos los objetos que empezaban con esa letra. Que las palabras estaban vivas. Lo cual por otro lado era una intuición muy verdadera: las palabras nacen en una época, tienen un biografía, algunas mueren. Entonces las enumeraciones responden a una cosa lúdica: es el gozo de nombrar, la cosa panteísta de que el lenguaje está para nombrar las cosas, y lo primero es el verbo. Es entonces, un poco pagar tributo al gusto de nombrar. 
En cuanto a los finales y a la digresión, sucede que en último término a uno le cuesta mucho renunciar a todas las posibilidades de algo, ¿no? Creo que sólo cuando somos grandes aprendemos a decirnos que no a algunas cosas. Y no sé si eso es algo que esté bien, que haya que alabar. Entonces las digresiones son algo que se plantea al lector: "yo de todas las cosas posibles tengo que elegir una, tengo que renunciar a muchísimas, pero si usted quiere seguir por aquí, siga ...". Porque la verdad es que cuando a partir de una idea escribís una historia, ésta es una de las historias posibles. Un ejemplo de este tipo de cuento es "Los bañistas" [de El museo de los esfuerzos inútiles, 1983].

Ahora también es cierto de otros cuentos que ocurre lo contrario, donde la lógica es indefectible, que son ésos o nada. Un ejemplo es "El juicio final" [de Una pasión prohibida, 1986], en que el tipo termina haciéndole el reproche a Dios. El final ahí pudo solamente ser uno. Yo diría que cuando son simbólicos los cuentos, tienen una sola posibilidad. Ya están escritos. En cambio, si son líricos, por ejemplo, te permiten todo tipo de juego. Y lo lírico y lo lúdico están muy cercanos, ¿no? En el cuento lírico te podés permitir un guiño a ti mismo, que no te podés permitir en un cuento simbólico, donde si cometés una digresión innecesaria, arruinás la metáfora general.

\section{EL ESCRITOR Y EL MUNDO (MODERNO)}

Estoy totalmente de acuerdo con Rimbaud: para escribir hay que ser completamente moderno. A mi me parece que el escritor tiene que dar una respuesta, tiene que expresar lo que es el ambiente de su momento. Y el fenómeno éste nuevo de las grandes concentraciones urbanas, de las ciudades como Barcelona, ciudades hipertrofiadas por un lado, y por otro lado donde no queda lugar para lo sacro, ¿no? Porque por lo menos en las civilizaciones rurales, en la cultura rural el hombre tiene una relación con el tiempo, con las estaciones, con la tierra, que en algún lugar lo comunica con lo trascendente. Pero en los espacios modernos lo que hay es la angustia. A mí por un lado me gusta vivir en una ciudad moderna, a pesar de que las padezco mucho, en el sentido de que me dan una visión de la civilización, de para dónde va esta locura.

Intento ser un escritor moderno en la medida en que me parece que asumo las circunstancias de la gente. No hay una novela en España en este momento sobre el fenómeno, de estos diez últimos años, que es el parado. No la hay, entre otras cosas, porque los escritores de aquí, los europeos, ya han perdido la vinculación con lo social. Vos decís, y está muy bien, que la literatura que yo hacía en Uruguay respondía a las inquietudes de esa época, porque todavía en nuestras sociedades la literatura sigue siendo decimonónica. ${ }^{1}$ No en cuanto a estilo: es decimonónica en cuanto a que hay una relación entre la vida y la literatura. La literatura todavía es una manera de responder.

\footnotetext{
${ }^{1}$ Ver mi artículo "Phantastic Political Allegory in the Early Work of Cristina Peri Rossi", Bulletin of Hispanic Studies, LXVII (1990), 151-164.
} 
En Europa y en Estados Unidos la literatura ya es una profesión. Entonces vos no te encontrás aquí a los escritores caminando por la calle. No viven en los barrios bajos, donde vivo yo. Viven en los barrios altos, donde no hay contaminación, no hay parados; entonces, es un mundo artificial, porque es la minoría la que vive ahi. De manera que no porque vayas a hacer una literatura fácil, sino sencillamente porque los problemas de la sociedad son los de la mayoría de la gente, no los de la minoría. Para que un escritor sepa lo que es un parado, tiene que vivir en un barrio de parados.

\section{LA LITERATURA FEMINISTA Y LA PSICOLÓGICA}

A mí no me preocupa mucho el tema. Siempre me acuerdo de que cuando publiqué Viviendo, que son tres cuentos protagonizados sólo por mujeres, una amiga mía, una mujer mayor, que por más datos era lesbiana, me escribió una carta que no me gustó nada porque me acusaba de que porque yo era lesbiana solamente había hablado de mujeres. Resulta que después, hago siempre protagonistas masculinos, y las lesbianas me dicen que por qué no hablo de mujeres. Entonces me parece que en ese sentido no hay que darles piola a los lectores. Hay que moverse de acuerdo a las necesidades autonómicas de lo que vas a narrar. Si uno hace literatura psicológica, entonces sí uno puede construir personajes femeninos interesantes. Yo no hago una literatura psicológica. En todo caso, lo que me interesa de la psicología son las cosas que no tienen sexo: las neurosis, las paranoias, pues en realidad la gama de las fantasías enfermizas excluye el sexo. Es decir, no es distinto el mundo persecutorio de una paranoica que el de un paranoico.

Los psicoanalistas cuentan que las fantasías paranoicas no son más de 99 , en todas partes del mundoy en todas las épocas. No hay un registroimpresionante. Claro, como son fantasías muy arcaicas, que pertenecen probablemente a temores muy primitivos, forman parte ya casi de respuestas instintivas a temores que una vez tuvimos. Entonces en ese sentido me parece que si se hace una literatura simbólica, lo simbólico no tiene sexo. En cambio, si se hace una literatura específicamente psicológica, ahí sí se pueden crear personajes femeninos interesantísimos puesto que la verdad es que en estos últimos diez o quince años, creo que todos estamos bastante de acuerdo en que hay una cantidad de mujeres interesantes. Las hay en la realidad, no te las tenés por qué soñar. Lo que pasa es que el pasaje de la realidad a la literatura tarda un poco; entonces, que haya una cantidad de mujeres interesantes todavía no hace nada en cuanto a la condición femenina en general. La condición femenina en general sigue siendo la de mí vecina, a pesar de que hay 500 mujeres interesantes en España.

Yolo psicológicolo siento demasiadocomo para tener ganas de enchastrarme los dedos con eso. Lo percibo demasiado. Para mí no forma parte de lo imaginario, y a mí me interesa más lo imaginario. Además, se ha modificado 
tanto nuestra visión de lo psicológico que en realidad quizás en este momento lo más difícil, lo más tramposo, es hacer una novela psicológica, porque quizás ya no haya un punto de vista desde el cual hacerlo. Lo psicológico sigue siendo casi decimonónico frente a lo que ha sido la gran incursión del psicoanálisis y demás. Por eso yo elijo lo imaginario en el sentido de lo paranoico, lo neurótico, mucho más que la creación de un personaje con una singularidad muy especial. Yo creo que la única escritora que tocó eso fue Clarice Lispector.

\section{EL SADISMO}

Creo que el sadismo es culturalmente masculino. La cultura masculina es una cultura competitiva. Eso está íntimamente vinculado con el poder. A mí me encanta el fútbol, pero es una ceremonia competitiva, donde incluso todo el lenguaje es bélico. Para el hombre la guerra ha sido la actividad fundamental. Luego se consiguió sustituir por los combates simbólicos: conseguir la pelota, lidiar toros. Por otro lado esto me gusta en el sentido de que hay que dar una salida a la agresividad.

Pero entonces, nos preguntamos, ¿qué ha hechola mujer con su agresividad, con su propia agresividad? Yo no puedo creer que la mujer y el hombre sean tan distintos como para que la mujer no tenga agresividad. Lo que sucede es que ha habido un cultivo sólo de la agresividad culturalmente masculina, y que eso sí crea errores. Si hay una raza que cultiva culturalmente su agresividad, tiene que haber también unos objetosque reciban esa agresividad, sean los toros, sean las mujeres. Hay un barrio periférico de Madrid que se llama Vallecas, que tiene un equipo de fútbol que se llama Rayo Vallecano. Y los domingos, si el Rayo Vallecano gana, los hombres les pegan a las mujeres, y si pierde, los hombres también les pegan. O sea que no hay solución. Quienes reciben la agresividad del mundo competitivo del hombre, son en general las mujeres, víctimas propiciatorias, porque están allí y porque son más débiles físicamente.

En cualquier sociedad, los rituales de desfloración son sádicos, y yo no voy a creer que es porque todas las mujeres son masoquistas. Algunas habrá, pero no todas. Entonces, si ves el lenguaje del fútbol, el ataque, la defensa, y lo pasas al mundo del sexo, la penetración, vemos cómo estamos en mundos bélicos. La conquista del campeonato es lo mismo que la conquista de la mujer.

Uno de los textos más violentamente sádicos que he leído es el de la penetración anal de la amante en Libro de Manuel. Eso loinvestigóbien Bataille cuando habla de la perversión y la inocencia. La perversión como la conquista de la inocencia del otro. Lo perverso es saber una cosa que el otro no sabe. Creo que ése ha sido el secreto de la cultura masculina: violar la inocencia es perverso. Si la mujer se casaba, lo hacia en la más completa inocencia. El hombre tiene un secreto, y él es el que pervierte, desde el lugar del que conoce, el que pervierte la inocencia ajena. La mujer se vuelve apetecible porque es inocente, no porque es igual. Eso es básicamente sádico: si yo sé algo que vos no sabes, y porque vos no lo sabés es que me gustás, no porque lo sabés. Esa es 
la relación básica, además, de hombre mayor con niña pequeña. Si se mira la civilización occidental, el hombre siempre, hasta hace muy poco, tiene más años que la mujer.

\section{EL VALOR ESTÉTICO DE LA PERVERSIÓN}

En sociedades muy patriarcales la inocencia de una mujer, el hecho de que no sepa, la convierte en víctima propiciatoria de una ceremonia, la perversión, que a mí, desde el punto de vista de la literatura me parece el gran tema de Occidente. Estoy totalmente de acuerdo con que es de lo más atractivo del mundo. Lo que pasa es que hay unas víctimas, entonces, desde el punto de vista moral, no puedo estar de acuerdo, aunque de pronto, estéticamente, sí. Pero yo no jugaría el otro rol. Si me dejan elegir [en el mundo real] como mujer, no puedo elegirlo. En el imaginario, si lo tengo que elegir, claro, me pongo del lugar del hombre. Yo también quiero disfrutar del secreto. No quiero ser la víctima propiciatoria. Quiero ser quien tiene el secreto.

La escena de Libro de Manuel es sádica pues le hace a la mujer algo que ella no quiere que se le haga. Por lo tanto el placer está en el "te someto a lo que no querés". Y, además encima, con ese lugar común de: "cuando decís no en realidad querés decir que sî", [la justificación metafísica de Andrés] expresa una fantasía. No es que yo lo rechace literariamente: lo veo como el exponente de otra fantasía masculina.

\section{LAS MUJERES COMO LO OTRO}

No hay una tradición de erotismo que tenga como objeto al hombre. Lo universal sigue siendo varón, europeo y blanco, quiere decir que las mujeres en último término o son fantasías de los hombres o no existen todavía. $\mathrm{Y}$ las mujeres rebeldes son aquellas que no quieren ser la fantasía de nadie, que quieren ser su propia fantasía. Y como la literatura la han hecho los hombres, nos encontramos frente a un universo de fantasias masculinas. Esa es la tradición del lector. Yo lo que digo es que, por ejemplo "La metamorfosis" sólo puede ser protagonizada por un personaje masculino, porque para ser una mujer tendria que haber escrito Kafka otras 50 páginas para crear un personaje femenino singular para que le pasara eso. Entonces, dado que las mujeres recién empiezan a escribir, están muy preocupadas por la búsqueda de su identidad, para contar las cosas que les pasa; por lo tanto todavía no hay creado un mundo imaginario, de fantasías. Y ahí tendriamos que hablar mucho y yo no tengo una posición fija sobre si realmente la mujer alguna vez tiene otra fantasía que no sea ella misma. Sobre si el hombre puede llegar a ser objeto de la fantasía de una mujer, me parece que se podria hablar mucho.

Lo que pasa es que la literatura y el arte están llenos de fantasias masculinas. Esto es muy complejo porque conocemos las fantasías de los hombres. Las fantasías de la mujeres han sido su propio secreto. Hay un lugar 
en que creo que la mujer sólo tiene fantasías acerca de sí misma, y en ese sentido es que puede ser lo otro para el hombre. Es decir, lo inalcanzable siempre, e incluso puede provocar el sadismo por ser siempre lo inalcanzable. No es una cosa general, estamos hablando con una matización profunda, en el sentido de que estas cosas no son culturalmente genéricas, pero yo pienso que la mujer sólo ha tenido un imaginario acerca de sí misma. Casi no ha tenido un imaginario del mundo, le ha costado tener un imaginario porque no tenía experiencia del mundo. Y es muy difícil que el hombre se convierta en un objeto de deseo para la mujer.

En realidad lo que se convierte en objeto de deseo de la mujer es el deseo que tiene el hombre de ella. A lo sumo, lo que desea en general una mujer es el deseo de ella que tiene el hombre. En cambio, el hombre desea lo otro, es decir, el hombre desea a la mujer. La mujer se desea a sí misma a través del deseo del otro. La frase más común de una mujer satisfecha es "me haces el amor como yo me lo haría a mí misma”.

\section{EL ENIGMA DE LA NAVE DE LOS LOCOS (1984)}

El enigma se resuelve porque él habla de la castración de la virilidad y no del sexo. Incluso hubo malentendidos. Yo pensaba que lo había salvado perfectamente el final, y después, en varias entrevistas que me hicieron, me di cuenta de que, incluso gente que uno supone que tiene buen nivel, entendió mal el final. El final no dice que lo que tiene que amputarse Equis es el sexo. Él lo que tiene que sacrificar es la virilidad, que es un concepto cultural. La virilidad como ha sido en esta cultura ... no es el sexo; no es una obliteración del sexo; no es que se castra para poder amar a una mujer. Lo que quiere amputarse es la virilidad tradicional, la manera tradicional de enfrentarse a una mujer. A mí me parecería totalmente aberrante pensar que hay que sacrificar la heterosexualidad. Tiene que modificarse la heterosexualidad a favor de una sexualidad que no sea ya sólo el patrón de la sexualidad masculina. Que le permita el placer a la mujer también. Pero de ninguna manera eso pasa por una sociedad donde no hay heterosexuales.

El eje de toda la novela es el no practicar la agresividad, no dirigir la agresividad hacia los demás. Y en realidad todos son víctimas de distintas agresiones. Todo lo que aparece son aparentemente relaciones aberrantes, pero justamente son las únicas donde hay amor. En realidad es saltarse la norma para poder sentir de veras. 